\title{
Human Monoclonal Antibodies That Recognize Conserved Epitopes in the Core-Lipid A Region of Lipopolysaccharides
}

\author{
Matthew Pollack, ${ }^{\star}$ Andrew A. Raubitschek, ${ }^{\ddagger}$ and James W. Larrick ${ }^{\ddagger}$ \\ *Department of Medicine, Uniformed Services University of the Health Sciences, F. Edward Hébert School of Medicine, Bethesda, \\ Maryland 20814; and ${ }^{\ddagger}$ Department of Immunology, Cetus Corporation, Palo Alto, California 94303
}

\begin{abstract}
Epstein-Barr virus (EBV)-transformed human B lymphocytes were fused with a murine-human heteromyeloma to produce stable hybrid cell lines that secreted human monoclonal antibodies (mAbs) of the IgM class that recognized conserved epitopes in the core-lipid A region of lipopolysaccharides (LPS). Three of the $\mathrm{mAbs}$ reacted with epitopes on the lipid A moiety, while a fourth recognized a determinant in the core oligosaccharide. The lipid A-specific mAbs cross-reacted with heterologous rough LPS and with lipid As released by acid hydrolysis of different intact (smooth) LPS. Carbohydrate groups in the O-side chain and core oligosaccharide of isolated, smooth LPS restricted antibody access to antigenic sites on lipid A. Yet, one lipid A-reactive $m A b$ recognized its epitope on the surfaces of a variety of intact bacteria. These findings confirm the presence of highly conserved epitopes in the core-lipid A complex and prove the existence of human B cell clones with the potential for secreting high avidity IgM antibodies that react with these widely shared determinants. Such human mAbs might provide protective activity against disease caused by diverse gram-negative bacteria.
\end{abstract}

\section{Introduction}

Gram-negative bacteria are common pathogens of man. Lipopolysaccharides (LPS), ${ }^{1}$ or endotoxins, are an essential structural and immunopathogenic component of the outer cell membrane of all gram-negative bacteria $(1,2)$. LPS are complex, microheterogeneous macromolecules that share a tripartite structure that consists of lipid A, the core oligosaccharide, and O-specific side chain (3). Lipid A is the toxic moiety, and together with the covalently attached core oligosaccharide, constitutes the phy-

\footnotetext{
Address reprint requests to Dr. Pollack.

Presented at the International Symposium on the Immunobiology and Immunopharmacology of Bacterial Endotoxin, Tampa, FL, January 1985 , and at the International Symposium on Endotoxin, Bari, Italy, May 1986.

Received for publication 26 August 1986 and in revised form 13 January 1987.
}

1. Abbreviations used in this paper: AET-SRBC, aminoethylisothiouronium bromide-treated sheep erythrocytes; $C E N$, chicken erythrocyte nuclei; EBV, Epstein-Barr virus; ELISA, enzyme-linked immunosorbent assay; FACS, fluorescence-activated cell sorter; KDO, 3-deoxy-D-mannooctulosonic acid; LPS, lipopolysaccharide; $\mathrm{mAb}$, monoclonal antibody; PAGE, polyacrylamide gel electrophoresis; TBS, Tris buffer with saline; TBS-AGT, TBS with albumin, gelatin, and Tween-20.

The Journal of Clinical Investigation, Inc.

Volume 79, May 1987, 1421-1430 logenetically conserved core region of LPS $(3,4)$. The distally linked O-side chain, on the other hand, represents a hypervariable region that determines the antigenic diversity of bacterial LPS $(5,6)$.

It has been proposed that antibodies that recognized conserved epitopes in the core-lipid A region of LPS would crossreact among a wide variety of gram-negative bacteria and would possess antiendotoxic activity based on their ability to neutralize or block lipid A-mediated biological activities (7). It has been further speculated that such antibodies, because of their broad cross-reactivity and putative antiendotoxic properties, would serve a protective function in gram-negative sepsis of diverse etiology. Moreover, since serum antibodies that react with LPS core determinants are prevalent among normal adults $(8,9)$, these antibodies have been regarded as an important component of natural immunity against gram-negative bacterial disease. Accordingly, augmentation of such antibodies through active or passive immunization has been viewed as a potential means for increasing host resistance to the septic complications of gramnegative infections. This possibility has been evaluated, both in experimental animals $(10,11)$ and in man $(12)$, through immunization with rough mutants of certain gram-negative bacteria whose incomplete LPS is comprised of antigenically exposed core structures containing lipid $A$ and basal core sugars $(5,13)$. These studies have proven inconclusive, however, on the basis of variable protection or the failure to correlate protection with antibodies of defined specificity.

The availability of monoclonal antibodies (mAbs) with specificities for well-defined epitopes in the LPS core region would permit critical immunochemical analysis of this portion of the LPS macromolecule as well as functional evaluation of the antibodies themselves. We have recently reported the preparation of such mAbs, of both murine (14) and human origin (15), and confirmatory data have come from several other laboratories $(16-20)$. We describe here the preparation of stable hybrid cell lines that secrete human mAbs that recognize conserved epitopes in the core-lipid A region of LPS. Characterization of these antibodies confirms the presence of highly conserved antigenic structures in the core-lipid A complex and proves the existence of human B cell clones capable of secreting high avidity antibodies that react with these widely shared determinants. These mAbs with core-lipid A specificity may be assayed directly for their protective effect and as prophylactic and/or therapeutic agents for diseases caused by gram-negative bacteria.

\section{Methods}

Bacterial strains. The uridine diphosphate-4-galactose epimerase-deficient Escherichia coli J5 mutant (13) was obtained from A. I. Braude (University of California, San Diego, CA). The heptoseless Salmonella minnesota $\mathrm{R} 595$ mutant (Re chemotype) (5) was obtained from L. S. Young (University of California, Los Angeles, CA). The E. coli 0111:B4 and $S$ 
minnesota wild-type strains were obtained from L. Shoer (List Biological Laboratories, Inc., Campbell, CA). Clinical isolates were obtained from the clinical microbiology laboratory, Naval Hospital, Bethesda, MD.

Lipopolysaccharides (LPS), lipid A, and part structures. Rough and smooth LPS, purified by Galanos (21) and modified Westphal procedures (22), respectively, and further purified chromatographically, were obtained from List Biological Laboratories. Quantitative analyses of 19 LPS preparations used were provided by the manufacturer. $14(74 \%)$ contained $<1 \%$, and all 19 contained $<1.5 \%$ nucleic acid by weight. $11(58 \%)$ contained $<1 \%$, and all 19 contained $<2 \%$ protein by weight. Lipid As, prepared by acetic acid hydrolysis of Re mutant LPS (23), were obtained from List or from Ribi Immunochem Research, Inc., Hamilton, MT. Monophosphoryl lipid A (24), derived from Re mutant $S$. minnesota LPS, was obtained from Ribi. The lipid A precursor molecule designated lipid X (25), was purchased from Lipidex, Middleton, WI.

Enzyme-linked immunosorbent assays (ELISA). Antibody reactivity with rough and smooth LPS, and lipid A, was measured by ELISA, as previously described (8). Briefly, LPS (or lipid A) dissolved in carbonate coating buffer ( $15 \mathrm{mM} \mathrm{Na}_{2} \mathrm{CO}_{3}, 30 \mathrm{mM} \mathrm{NaHCO}_{3}, 3 \mathrm{mM} \mathrm{NaN}_{3}, \mathrm{pH}$ 9.55), at a concentration of $10-25 \mu \mathrm{g} / \mathrm{ml}$, was incubated at $4^{\circ} \mathrm{C}$ overnight in polystyrene microtiter plates (Dynatech Laboratories, Inc., Alexandria, VA). The wells were washed with phosphate-buffered saline (PBS, pH 7.4) containing $0.5 \mathrm{ml} /$ liter of Tween-20 (PBS-Tween). Then, $50 \mu \mathrm{l}$ antibody-containing test samples (suspended in PBS-Tween) were incubated in the wells at $4^{\circ} \mathrm{C}$ for $30 \mathrm{~min}$. The final three steps, separated by PBSTween washes, were as follows: addition of $50 \mu \mathrm{l}$ of rabbit anti-human Ig (Zymed, South San Francisco, CA) diluted 1:500, followed by incubation at $4^{\circ} \mathrm{C}$ for $30 \mathrm{~min}$; addition of $50 \mu$ of goat anti-rabbit IgGalkaline phosphatase conjugate (Sigma Chemical Co., St. Louis, MO); addition of $50 \mu \mathrm{l}$ of $p$-nitrophenylphosphate substrate (Sigma 104), $1 \mathrm{~g}$ / $\mathrm{ml}$ in $10 \%$ diethanolamine, $\mathrm{pH} 9.8$, followed by incubation at $25^{\circ} \mathrm{C}$ for $60 \mathrm{~min}$. Absorbance was read at $405 \mathrm{~nm}$ in a Titertek Multiscan MicroELISA Spectrophotometer (Flow Laboratories, Inc., McLean, VA).

Competitive inhibition ELISA was performed by dispersing freshly prepared and sonicated LPS (or lipid A) in normal saline containing 1 $\mu \mathrm{l} / \mathrm{ml}$ of triethylamine. 10 -fold dilutions of the LPS suspension were preincubated at $37^{\circ} \mathrm{C}$ for $1 \mathrm{~h}$ with a predetermined amount of antibody that yielded an optical density of $\sim 1.0$ when assayed alone in the ELISA. The LPS-antibody mixture was then assayed by ELISA, as described above, and percent inhibition of antibody binding activity calculated for each concentration of inhibitor by the following formula: $1-O_{405}$ of $\mathrm{mAb}+\mathrm{LPS} / \mathrm{OD}_{405}$ of $\mathrm{mAb}$ alone $\times 100$.

A whole bacterial cell ELISA was performed as follows. Bacteria were grown overnight at $37^{\circ} \mathrm{C}$ in tryptic soy broth (Difco Laboratories, Detroit, MI), heat-killed at $100^{\circ} \mathrm{C}$ for $10 \mathrm{~min}$, washed three times in normal saline, and suspended in carbonate buffer $\left(15 \mathrm{mM} \mathrm{Na}_{2} \mathrm{CO}_{3}, 30\right.$ $\mathrm{mM} \mathrm{NaHCO}_{3}, 3 \mathrm{mM} \mathrm{NaN}_{3}, \mathrm{pH} 9.55$ ) to an optical density at $660 \mathrm{~nm}$ of 0.2 . 50- $\mu \mathrm{l}$ aliquots of the bacterial suspension were added to the wells of a 96-well microtiter plate containing $0.22 \mu \mathrm{m}$ pore-sized polyvinylidene fluoride membranes (Millititer GV Filtration Plate, Millipore Corp., Bedford, MA) and the plates incubated overnight at $4^{\circ} \mathrm{C}$. Subsequent steps were identical to those described above except that removal of reagents from wells and washing were accomplished by means of a small aperture in the bottom of each well leading to a vacuum manifold plate holder. After addition of substrate, filtrates were transferred into the wells of a second, standard microtiter plate placed in the vacuum chamber immediately below the filtration plate, and optical density determined at $\mathbf{4 0 5} \mathrm{nm}$ in the automated spectrophotometer.

Preparation of hybridomas and mAbs. Peripheral blood mononuclear cells were separated on Ficoll-Hypaque (26) from blood obtained from individuals with high naturally acquired or immunization-induced ELISA titers to LPS from the heptoseless $S$. minnesota $\mathrm{R} 595$ mutant (Re chemotype) (5) or the uridine diphosphate (UDP)-4-galactose epimerasedeficient $E$. coli J5 mutant (Rc chemotype) (13). Monocytes were depleted by adherence to plastic and $T$ cells were removed by rosetting with aminoethylisothiouronium bromide-treated sheep erythrocytes (AET-SRBC) (27). Nonrosetting cells were incubated with $10 \times$ concentrated EBVcontaining supernatant from the B95-8 marmoset cell line (28) and dis- tributed into flat-bottom 96-well microtiter plates at a density of $10^{4}$ cells/well. Culture supernatants were screened by ELISA for binding activity against $E$. coli J5 and $S$. minnesota R595 LPS after 14-21 d of incubation. Cells from positive wells were expanded, retested, and subcultured at low density in round-bottom microtiter plates. After further expansion, the cells were fused with the back-selected, 6-thioguanine/ ouabain-resistant F3B6 mouse-human (NS1x human B cell hybrid) heteromyeloma cell line $(29,30)$. Hybridomas from this fusion were selected in medium containing $100 \mu \mathrm{M}$ hypoxanthine, $5 \mu \mathrm{g} / \mathrm{ml}$ azaserine, and 5 $\mu \mathrm{M}$ ouabain, screened by ELISA, and cloned by limiting dilution or isolation in soft agar $(31,32)$.

RNA and DNA analytical techniques. RNA was prepared from cells using established methods (33); RNases were inhibited with vanadylribonucleoside (34). Oligo-dT purified poly (A) ${ }^{+}$mRNA was electrophoresed in formaldehyde-containing gels and transferred to nitrocellulose (35). DNA was extracted from isolated nuclei (36). The nuclei were suspended in $50 \mathrm{mM}$ Tris- $\mathrm{HCl}, \mathrm{pH} 7.5$, containing $40 \mathrm{mM} \mathrm{NaCl}$ and 10 mM EDTA, and extracted by the method of Copeland et al. (37). DNAs were digested to completion with appropriate restriction enzymes (New England Biolabs, Boston, MA), electrophoresed in 0.7\% agarose gels, and transferred to nitrocellulose (38). Filters were hybridized to nicktranslated Ig constant region probes in the presence of $10 \%$ dextran sulfate (39). A human J chain probe was obtained from E. Max (National Institutes of Health, Bethesda, MD); a mouse $J$ chain probe was from $\mathbf{M}$. Koshland (University of California, Berkeley, CA); Ig constant region probes were the gift of A. Bothwell (Yale University, New Haven, CT); and an EBV genomic probe was received from J. Pagano (University of North Carolina, Chapel Hill, NC). After hybridization, filters were washed twice at $22^{\circ} \mathrm{C}$ in $0.015 \mathrm{M}$ sodium citrate containing $0.15 \mathrm{M} \mathrm{NaCl}$ and $0.1 \%$ SDS, and then washed twice more at $68^{\circ} \mathrm{C}$ in the same solution diluted 1:10 in water. The filters were then dried and exposed to $x$-ray film overnight at $-70^{\circ} \mathrm{C}$ with an intensifying screen.

DNA profiles. Established protocols $(40,41)$ were modified as follows. Chicken erythrocyte nuclei (CEN) stored in 50\% ethanol were used as internal standards for fluorescence activated cell sorter (FACS) analysis and prepared according to the method of Diamond and Braylan (42). CEN were sedimented at $100 \mathrm{~g}$ for $5 \mathrm{~min}$ at $4^{\circ} \mathrm{C}$, separated from the supernatant, and processed as described below. Cell lines were dispensed, in aliquots of $4 \times 10^{5}$ cells, into $15-\mathrm{ml}$ conical centrifuge tubes, washed, and resuspended in $1 \mathrm{ml}$ of isotonic PBS, $\mathrm{pH}$ 7.4. The cells were centrifuged at $100 \mathrm{~g}$ for $5 \mathrm{~min}$ at $4^{\circ} \mathrm{C}$, the supernatant was aspirated, and the cells resuspended gently in cold citrate solution containing $1 \mathrm{mg} / \mathrm{ml}$ sodium citrate, $\mathrm{pH} 7.5,11 \mathrm{mM} \mathrm{MgCl}$, and $15 \mu \mathrm{g} / \mathrm{ml} \mathrm{RNase} \mathrm{I-AS} \mathrm{(Sigma}$ Chemical Co.). The cell suspensions were incubated on ice for $10 \mathrm{~min}$ before the addition of $10 \mu \mathrm{l}$ of propidium iodide, $5 \mathrm{mg} / \mathrm{ml}$ in distilled water (Sigma Chemical Co.) and maintenance at room temperature for $30 \mathrm{~min}$. Samples were then placed on ice and filtered through $37 \mu \mathrm{m}$ nylon mesh before analysis.

An EPIC V cell sorter equipped with a 76- $\mu \mathrm{m}$ nozzle (Coulter Electronics, Hialeah, FL) was used for DNA content and forward-angle light scatter measurements. A 488-nm argon ion laser line at $1 \mathrm{~W}$ light regulated power was used for excitation, and the total fluorescent emission above $610 \mathrm{~nm}$ was measured. Forward angle light scatter was obtained as a measure of cell size with a neutral-density $2.0 \mathrm{OD}$ filter placed in front of the scatter detector. Two parameter $(64 \times 64$ channel $)$ DNA vs. scatter histograms and 256-channel histograms were generated with $\sim 10,000$ cells analyzed per cell line. Software- and hardware-based gated analysis, on DNA content and scatter, was employed to reduce debris and cell aggregate events.

Immunoblot analysis. LPS or lipid A samples were dispersed in water by heating and sonication, and mixed with an equal volume of $0.1 \mathrm{M}$ Tris-HCl buffer, $\mathrm{pH} 6.8$, containing $2 \%$ (wt/vol) SDS, $20 \%$ (wt/vol) sucrose, $1 \% 2$-mercaptoethanol, and $0.001 \%$ bromophenol blue. The samples were run in a Laemmli SDS-polyacrylamide gel electrophoresis system (PAGE) (43), using the slab apparatus described by Maizel (44), in which was employed a $4 \%$ stacking gel and a $14 \%$ separating gel incorporating $4 \mathrm{M}$ urea. The sample mixtures were heated in a $100^{\circ} \mathrm{C}$ water bath for $5 \mathrm{~min}$, applied in 10-20- $\mu$ l aliquots to a $140 \times 120 \times 1.2 \mathrm{~mm}$ 
slab gel, and electrophoresed at $20 \mathrm{~mA} / \mathrm{gel}$ until the bromophenol blue had migrated $10 \mathrm{~cm}$. The gel was then fixed by overnight incubation in a solution containing $40 \%$ ethanol and $5 \%$ acetic acid, and silver-stained according to the method of Tsai and Frasch (45).

LPS was transferred from identical, unstained companion gels according to the procedure of Towbin (46), as modified by Hitchcock (47), onto nitrocellulose membranes (Bio-Rad Laboratories, Richmond, CA) employing a transphor electrophoresis cell (TE42, Hoefer Scientific Instruments, San Francisco, CA). Transfers were performed in the cold employing a current of $125 \mathrm{~mA}$ for $20 \mathrm{~h}$. Immunoblots were developed in the following manner. Nitrocellulose membranes containing transferred LPS were immersed for $10 \mathrm{~min}$ in Tris buffer with saline (TBS) containing $20 \mathrm{mM}$ Tris- $\mathrm{HCl}$ and $150 \mathrm{mM} \mathrm{NaCl}, \mathrm{pH}$ 7.5. Membranes were then immersed, with gentle agitation for $30 \mathrm{~min}$, in blocking solution consisting of TBS plus $2 \%$ bovine serum albumin (BSA) and $0.25 \%$ gelatin. Membranes were then immersed in a solution containing the primary antibody, appropriately diluted in TBS plus $2 \%$ BSA, $0.25 \%$ gelatin, and $0.05 \%$ Tween-20 (TBS-AGT), and gently agitated for $2 \mathrm{~h}$. Membranes were washed with distilled water in TBS-AGT and incubated for $2 \mathrm{~h}$ with a second antibody (e.g., rabbit anti-human IgM) at an appropriate dilution. Membranes were then washed as before and incubated with a third antibody (e.g., goat anti-rabbit IgG) conjugated with peroxidase and diluted appropriately in TBS-AGT. Color was developed by the addition of chloronaphthol substrate $(60 \mathrm{mg}$ in $20 \mathrm{ml}$ of cold methanol mixed at room temperature with $100 \mathrm{mg}$ of TBS to which $60 \mu \mathrm{l}$ of cold $30 \% \mathrm{H}_{2} \mathrm{O}_{2}$ had just been added), and color development stopped by immersing nitrocellulose membranes in several changes of distilled water.

Estimation of antibody avidity. The solid-phase radioimmunoassay system employed was adapted from that previously described by Frankel and Gerhard (48) and later modified by Mandrell and Zollinger (49), except that LPS (or lipid A) was the solid-phase antigen used to coat the wells of flexible polyvinyl microtiter plates (overnight incubation at $4^{\circ} \mathrm{C}$ at an appropriate LPS concentration, as indicated below). Serial dilutions of $\mathrm{mAb}$, prepared by ammonium sulfate precipitation of hybridoma tissue culture supernatant obtained under serum-free conditions, were incubated overnight at room temperature in LPS-coated microtiter plates. The amount of specific antibody bound at each dilution was determined by subsequent incubation with ${ }^{125}$ I-labeled goat anti-human immunoglobulin. The resulting counts per minute were related to a standard curve generated by means of a capture assay in which known amounts of human immunoglobulin of the appropriate class were added to microtiter wells previously treated with a class-specific rabbit anti-human immunoglobulin and detected with class-specific ${ }^{125}$ I-labeled goat antihuman Ig. Antibody concentration at each dilution was determined by assaying a single antibody dilution in microtiter wells coated with increasing concentrations of LPS (lipid A) and establishing the peak antibody concentration above which no additional binding occurred with increasing amounts of antigen; the antibody concentration determined at this single dilution was then used to calculate the antibody concentration of other dilutions by multiplying by the appropriate dilution factor. After quantitation of total LPS-specific antibody and antibody bound at each dilution, a Scatchard plot was constructed of antibody bound/free antibody vs. antibody bound, and $K_{\text {eq }}$ determined by the following formula: $-n K_{\mathrm{eq}}=$ antibody bound/total antibody - antibody bound, where $n=$ antibody valence (assumed to be 10 in the case of IgM).

LPS hydrolysis (23). $1 \mathrm{mg}$ of purified smooth LPS was mixed with $3 \mathrm{ml}$ of $1 \%$ acetic acid in a 10 -ml capacity round-bottom flask. The mixture was refluxed for $2 \mathrm{~h}$ at $100^{\circ} \mathrm{C}$, allowed to cool, and adjusted to pH 7.5 with $2 \mathrm{~N} \mathrm{NaOH}$. The hydrolyzed LPS was then diluted 1:10 in coating buffer and used to coat the wells of microtiter plates for determination of antibody binding in the ELISA (see above).

\section{Results}

Hybridomas secreting human mAbs reactive with the core-lipid A complex. After EBV transformation of peripheral blood mononuclear cells, only LPS core-specific antibodies of the IgM class were detectable. Antibody production was maintained in fewer than $5 \%$ of these cultures. In contrast, when EBV-transformed cells were fused with the F3B6 heteromyeloma, most fusions yielded clones with relatively stable core (or lipid A)specific antibody synthesis, including the four clones described here. Further stabilization of antibody production was achieved by cloning hybrids in soft agar and identifying high antibody producers using a reverse plaque technique $(31,32)$.

The cloned cell lines designated D-234, D-244, D-250, and D-267 have been maintained in continuous culture, without loss of antibody synthesis, for 12 mo or more. FACS analysis of the fused cell lines revealed a DNA content in excess of that demonstrated by the F3B6 heteromyeloma fusion partner (Fig. 1). Relative DNA content was characteristic for each hybridoma, and remained stable with time. Western blot analysis of the mAbs produced by each of the four cell lines demonstrated only human heavy and light chains. No human $\mathbf{J}$ chain was detected on Southern blots, while mouse $\mathrm{J}$ chain message was demonstrated on Northern blots. Finally, no DNA sequences corresponding to the EBV genome were revealed employing Southern hybridization techniques.

Specificity and cross-reactivity of $m A b s$. The mAbs referred to as D-234, D-244, and D-267 recognized determinants shared by $E$. coli J5 and $S$. minnesota R595 core glycolipids (Fig. 2). These antibodies demonstrated greater ELISA reactivity against isolated lipid As than against the glycolipids from which the lipid As were derived, and greater binding to the rough $S$. minnesota R595 LPS compared with the more complex $E$. coli J5 core glycolipid. D-250, on the other hand, reacted more selectively with $E$. coli J5 LPS, demonstrating little or no binding activity against $S$. minnesota R595 LPS or lipid A (Fig. 2). Subsequent studies indicated that the apparent binding of D-250 to $E$. coli $\mathrm{J} 5$ lipid A probably resulted from recognition of an epitope on the core oligosaccharide of contaminating unhydrolyzed, rough LPS rather than a determinant on the lipid A moiety itself. The difference in specificity between the group of mAbs comprised of D-234, D-244, and D-267, on the one hand, and $\mathrm{D}-250$, on the other, was confirmed by the strong reactivity of the former with isolated lipid As from $S$. typhimurium and $E$. coli $\mathrm{K} 12$ compared with the nonreactivity of D-250. None of the four mAbs reacted well with smooth LPS isolated from the

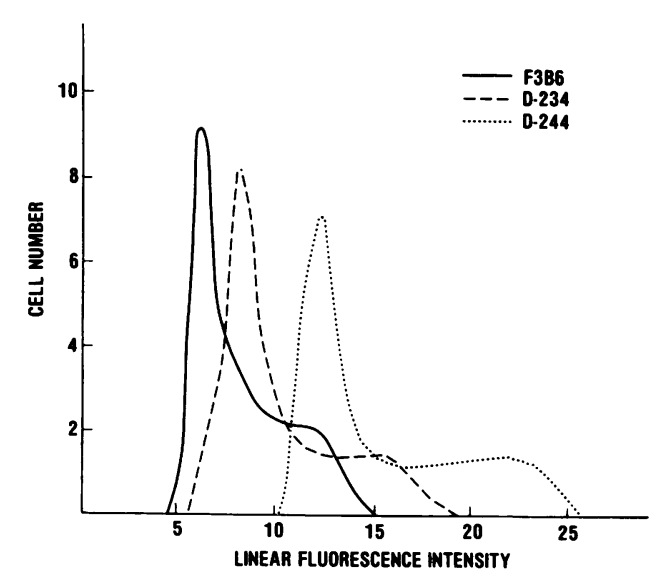

Figure 1. DNA histograms comparing the DNA content of the mAbsecreting D-234 and D-244 (EBV-transformed human B cell $\times$ F3B6) hybridoma cell lines to that of the F3B6 mouse-human (NS1 $\times$ human B cell hybrid) heteromyeloma fusion partner. 


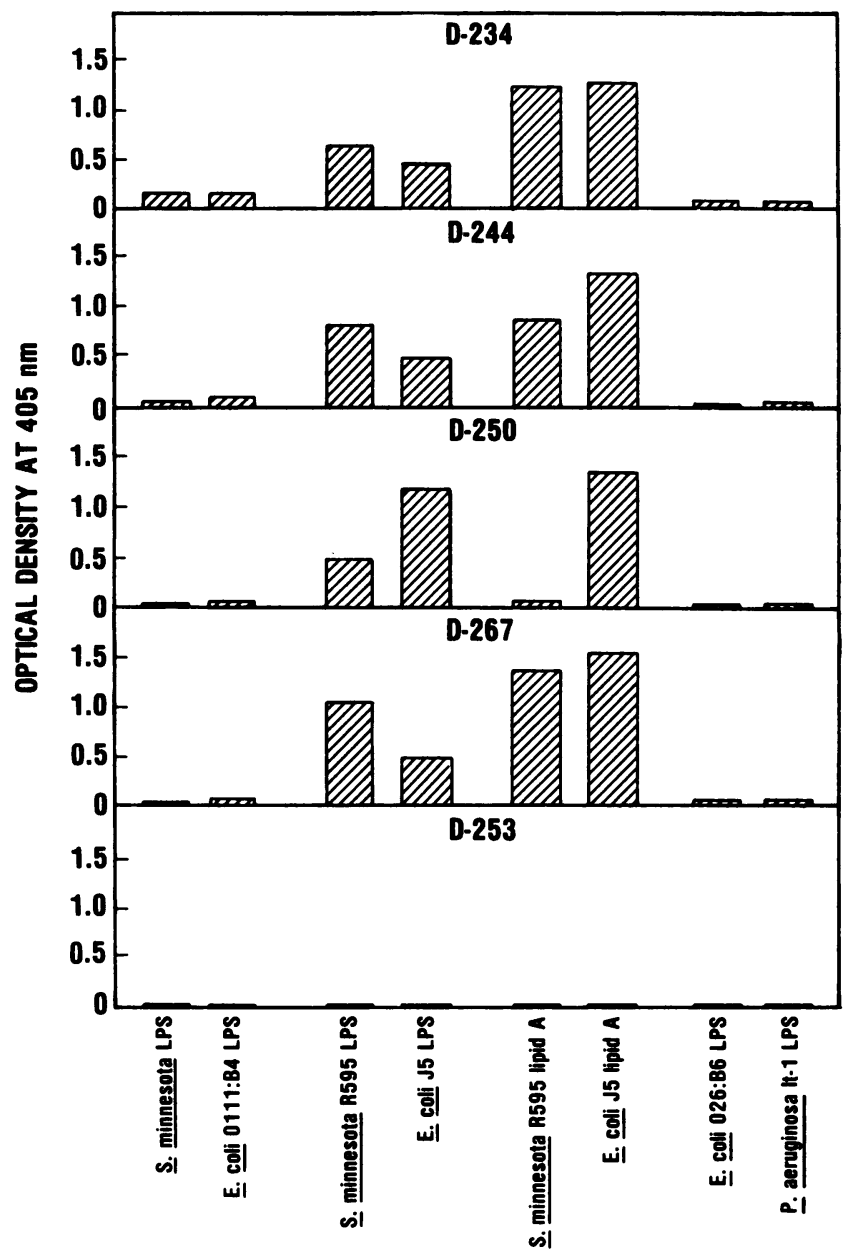

Figure 2. Binding activity of human mAbs against purified rough and smooth LPS, and lipid A, measured by ELISA. Partially purified mAbs were assayed at a concentration of $100 \mathrm{ng} / \mathrm{ml}$ in polystyrene microtiter wells coated with $25 \mu \mathrm{g} / \mathrm{ml}$ of LPS or $10 \mu \mathrm{g} / \mathrm{ml}$ of lipid A. The Pseudomonas aeruginosa toxin A-specific mAb designated D-253 (also an IgM) was included as a control.

E. coli 0111:B4 and S. minnesota wild-type parent strains from which the J5 and R595 mutants were derived, or with smooth LPS from the heterologous $E$. coli 026:B6 or P. aeruginosa Fisher immunotype 1 strains (Fig. 2). The human IgM mAb designated D-253, which reacts specifically with $P$. aeruginos $a$ toxin A and was included as a control, demonstrated no reactivity in the ELISA against rough or smooth LPS or lipid A. Together, these data indicated that three of the four mAbs described above recognized epitopes on the lipid A moiety shared by representatives of at least two phylogenetically distinct groups of gram-negative bacteria (i.e., the genuses Escherichia and Salmonella). The binding data further suggested that these epitopes were partially obscured by basal sugars contained in the incomplete core oligosaccharide of LPS from rough mutant strains and were more completely blocked by the intact core oligosaccharide and attached O-side chain of smooth, parent LPS. Finally, the more selective binding demonstrated by the D-250 antibody suggested its recognition of a sugar residue, i.e., glucose or heptose, contained in the abbreviated core oligosaccharide of the E. coli J5 mutant (8).
The ability of mAbs to recognize shared determinants on the core glycolipids of $E$. coli J5 and S. minnesota R595 was confirmed by competitive inhibition ELISA. The reactivity of mAbs D-234, D-244, and D-267 (the latter not shown) was inhibited by core glycolipids and by lipid As derived from the $E$. coli J5 and S. minnesota R595 rough mutant strains (Fig. 3). The greater inhibitory capacity of lipid As compared with core glycolipids, and of glycolipids compared with smooth parent LPS (Fig. 3), confirmed the specificity of the antibodies for epitopes on lipid A and their apparent stearic hindrance by carbohydrate moieties in the core oligosaccharide and O-side chain. Unlike the above antibodies, D-250 was inhibitable by $E$. coli J5 LPS, but not by the $S$. minnesota R595 core glycolipid or free lipid A (data not shown). This finding was consistent with the postulate that D-250 recognized an epitope on the incomplete core oligosaccharide of the $E$. coli $\mathrm{J} 5$ mutant distal to the corresponding 3-deoxy-D-mannooctulosonic acid (KDO) residue exposed on the more rudimentary core glycolipid of $S$. minnesota R595.

The lipid A specificity and cross-reactivity of particular mAbs, and the blocking of their epitopes by carbohydrate moieties in the $\mathrm{O}$ side chain and core oligosaccharide, were corroborated by examining the reactivity of these mAbs with smooth LPS that had been treated with acetic acid under conditions that cleaved the KDO and released free lipid A (23). The removal of the carbohydrate moieties resulted in the exposure of previously obscured epitopes on lipid A and enhancement in the

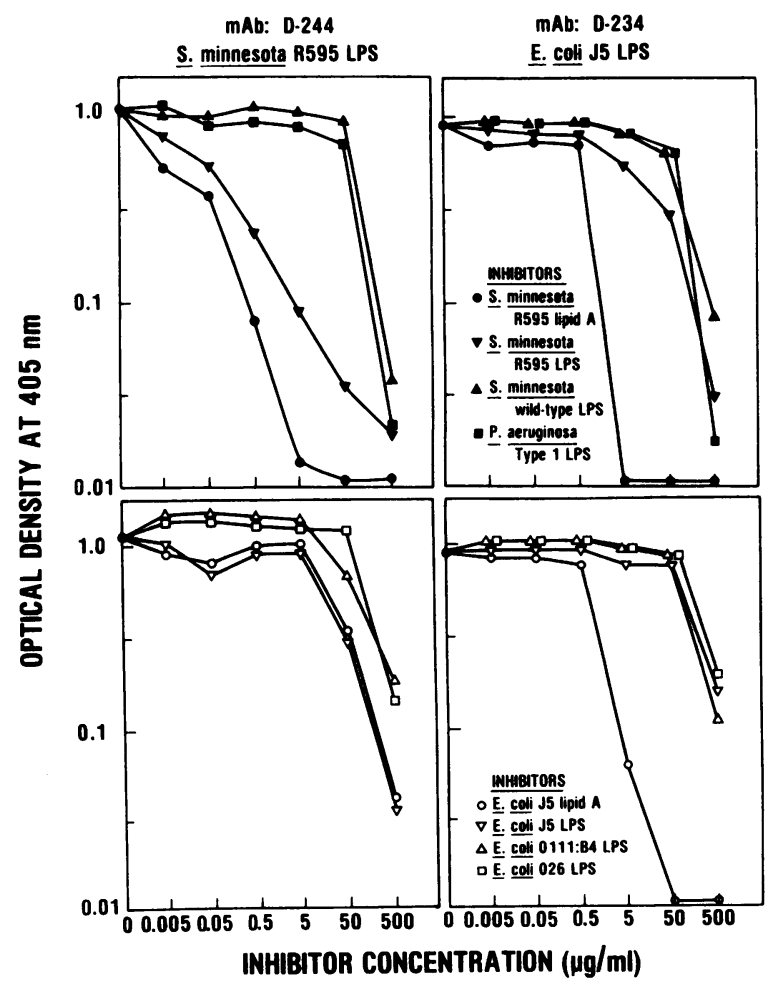

Figure 3. Competitive inhibition, in ELISAs, of the lipid A-reactive mAbs D-244 and D-234 by homologous and heterologous, rough and smooth LPS, and lipid A. Core glycolipids from the $S$. minnesota $\mathrm{R} 595$ and $E$. coli $\mathrm{J} 5$ rough mutant strains, which were used as solidphase antigens, are indicated above the left and right panels, respectively. Different LPS and lipid A inhibitors are designated by various symbols, as shown. 
reactivity of the lipid A-reactive mAbs (i.e., D-234, D-244, and D-267) with the hydrolyzed LPS (Table I). In contrast, acid hydrolysis of LPS produced relatively little or no increase in the reactivity of mAb D-250 with its epitope in the cleaved core oligosaccharide. The similar reactivity of lipid A-specific mAbs with hydrolyzed and unhydrolyzed LPS obtained from the $E$. coli $\mathrm{K} 12 \mathrm{D} 31 \mathrm{~m} 4$ rough mutant strain (Re chemotype) indicated that KDO residues, by themselves, did not restrict antibody access to epitopes on the lipid A moiety. These mAbs demonstrated somewhat less enhancement in binding activity against hydrolyzed Yersinia enterocolitica and Klebsiella pneumoniae LPS than against hydrolyzed $E$. coli and Salmonella LPS. Variable reactivity was noted against hydrolyzed Serratia marcescens and Pseudomonas aeruginosa LPS, and little binding was observed in the case of $V$. cholerae LPS in hydrolyzed or unhydrolyzed forms.

Reactivity of mAbs with whole bacteria. The demonstrated reactivity of mAbs with conserved epitopes in the core-lipid A region of LPS raises the question of whether such antibodies are able to recognize these epitopes on the surfaces of intact bacteria. This was examined in a whole cell ELISA employing, as solidphase antigens, the $E$. coli J5 and $S$. minnesota R595 rough mutant strains and various wild type clinical isolates. As indicated by the representative binding data shown in Fig. 4, the D-234, D-244, and D-267 mAbs reacted strongly with both $E$. coli J5 and $S$. minnesota $\mathrm{R} 595$ whole bacteria, corresponding to the isolated core glycolipids that these antibodies were previously shown to bind. D-250, on the other hand, demonstrated greater selectivity for $E$. coli $\mathrm{J} 5$ whole cells, which was similar to its specificity for isolated $E$. coli J5 LPS. While binding to whole, rough bacteria and corresponding isolated core glycolipids closely paralleled one another in the case of all four mAbs, an interesting divergence was noted in the case of smooth bacteria. In contrast to the other lipid A-reactive mAbs, D-244 and D-267, and the core oligosaccharide-reactive $\mathrm{mAb}, \mathrm{D}-250$, none of which reacted well with whole, smooth bacteria, D-234 demonstrated strong reactivity with a variety of clinical isolates (Fig. 4) despite its limited ability to bind isolated smooth LPS. In subsequent experiments (data not shown), maximal binding by D-234 to whole, smooth bacteria, obtained from carefully synchronized cultures, appeared to coincide with early $\log$ phase growth and to diminish markedly in late log and stationary phases.

Immunoblotting analysis. LPS consist of molecular species of varying molecular weight, reflecting variations in O-side chain length and core oligosaccharide integrity (50). Fast-migrating species can be resolved by SDS-PAGE carried out under reducing conditions and represent variants of the lipid A-core oligosaccharide complex. The exact mobility of such a complex depends upon lipid A substitution patterns and fatty acid composition, as well as the integrity of the core oligosaccharide. LPS molecules that contain a complete core structure and covalently attached O-side chains appear on such gels as regularly spaced, slower migrating bands, with adjacent bands representing LPS molecules that differ from one another by a single oligosaccharide subunit in the O-side chain (Fig. 5) (45).

Immunoblots were developed with mAbs after separation of LPS subcomponents on SDS-PAGE gels and electrophoretic transfer onto nitrocellulose membranes. In this type of immunoblotting analysis, the lipid A-reactive $\mathrm{mAb}, \mathrm{D}-234$, recognized its epitope only on fast-migrating species. Optimal reactivity was demonstrated by this antibody against Re chemotype LPS derived from S. minnesota (Fig. 5, lane 12) and E. coli $\mathrm{K} 12$ (strain D31 4 , lane 5), and against free lipid As obtained from $S$. minnesota, S. typhimurium, and E. coli $\mathrm{K} 12$ (lanes 13,15 , and 6). D-234 also recognized its antigenic determinant on the larger core structure of the $E$. coli J5 Rc chemotype mutant (Fig. 5, lane 2), and showed minor reactivity with LPS obtained from $S$. minnesota rough mutants representing the $\mathrm{Ra}, \mathrm{Rb}, \mathrm{Rc}$, and Rd chemotypes (lanes 8-11). In the latter instances, however, the equivalent, fast migration pattern of the blots suggested that D-234 was actually reacting with small amounts of free lipid A released from these core glycolipids rather than with the intact

Table I. ELISA Binding of Human Core-reactive mAbs to Intact and Hydrolyzed LPS from Various Gram-negative Bacteria

\begin{tabular}{|c|c|c|c|c|c|c|c|c|c|c|c|c|}
\hline \multirow[b]{2}{*}{ LPS } & \multicolumn{2}{|l|}{$\begin{array}{l}\mathrm{mAb} \\
\mathrm{D}-234\end{array}$} & \multicolumn{2}{|l|}{$\begin{array}{l}\mathrm{mAb} \\
\mathrm{D}-244\end{array}$} & \multicolumn{2}{|c|}{$\begin{array}{l}\text { mAb } \\
\text { D-267 }\end{array}$} & \multicolumn{2}{|l|}{$\begin{array}{l}\mathrm{mAb} \\
\mathrm{D}-250\end{array}$} & \multicolumn{2}{|l|}{$\begin{array}{l}\text { mAb } \\
\text { D-253 }\end{array}$} & \multicolumn{2}{|c|}{$\begin{array}{l}\text { Homologous } \\
\text { antiserum }\end{array}$} \\
\hline & I & $\mathbf{H}$ & I & $\mathbf{H}$ & $\mathbf{I}$ & $\mathbf{H}$ & I & $\mathbf{H}$ & I & $\mathbf{H}$ & I & $\mathbf{H}$ \\
\hline E. coli 0111:B4 & 0.37 & 1.36 & 0.02 & 0.74 & 0.03 & 0.54 & 0 & 0 & 0 & 0 & 1.91 & 1.67 \\
\hline E. coli 026 & 0.09 & 2.26 & 0.05 & 2.47 & 0.02 & 2.17 & 0.02 & 0 & 0 & 0.05 & 2.25 & 2.27 \\
\hline E. coli 055 & 0.01 & 2.22 & 0.13 & 1.52 & 0.01 & 2.27 & 0 & 0.18 & 0 & 0.18 & - & - \\
\hline E. coli 0127 & 0.22 & 2.19 & 0.02 & 2.06 & 0.03 & 2.07 & 0 & 0.01 & 0 & 0 & $0.09^{*}$ & $0.67^{*}$ \\
\hline E. coli $\mathrm{K} 235$ & 0.31 & 2.26 & 0.05 & 2.47 & 0.02 & 2.17 & 0.02 & 0 & 0 & 0.05 & - & - \\
\hline E. coli $\mathrm{K} 12, \mathrm{D} 31 \mathrm{~m} 4$ & 2.57 & 2.41 & 2.36 & 2.23 & 2.13 & 2.31 & 0 & 0.03 & 0 & 0.02 & - & - \\
\hline S. minnesota & 0.11 & 2.25 & 0.01 & 2.18 & 0 & 2.25 & 0 & 0.56 & 0 & 0.14 & 1.62 & 2.33 \\
\hline S. typhimurium & 0.04 & 2.11 & 0 & 1.94 & 0 & 1.94 & 0 & 0 & 0 & 0 & $0.14^{\ddagger}$ & $1.49^{\ddagger}$ \\
\hline Y. enterocolitica & - & 1.39 & - & 0.84 & - & 1.16 & - & 0.01 & - & 0 & 2.02 & 1.85 \\
\hline K. pneumoniae & - & 1.13 & - & 0.59 & - & 0.72 & - & 0.01 & - & 0.01 & 1.69 & 0.85 \\
\hline S. marcescens & - & 0.50 & - & 0.27 & - & 0.35 & - & 0.03 & - & 0.02 & - & - \\
\hline V. cholerae & 0.12 & 0.23 & 0.04 & 0.04 & 0.05 & 0.04 & 0.04 & 0.06 & 0.04 & 0.02 & - & - \\
\hline P. aeruginosa It-1 & 0.02 & 0.27 & 0 & 0 & 0 & 0.11 & 0 & 0 & 0 & 0 & 2.01 & 0.79 \\
\hline P. aeruginosa It-4 & 0.25 & 1.07 & 0 & 0.03 & 0.08 & 0.35 & 0 & 0 & 0 & 0.01 & $0.34^{\S}$ & $1.44^{8}$ \\
\hline
\end{tabular}

Antibodies were assayed at a concentration of $500 \mathrm{ng} / \mathrm{ml}$ in polystyrene microtiter wells coated with $10 \mu \mathrm{g} / \mathrm{ml}$ of intact LPS (I) or LPS hydrolyzed with $1 \%$ acetic acid at $100^{\circ} \mathrm{C}$ for $30 \mathrm{~min}(\mathrm{H})$. Results are expressed as optical densities at $405 \mathrm{~nm}$. Samples were run in triplicate, and standard errors averaged $5 \%$. * E. coli $0111: \mathrm{B} 4$ antiserum. ${ }^{\ddagger} S$. minnesota wild type antiserum. ${ }^{\$} P$. aeruginosa It-1 antiserum. 


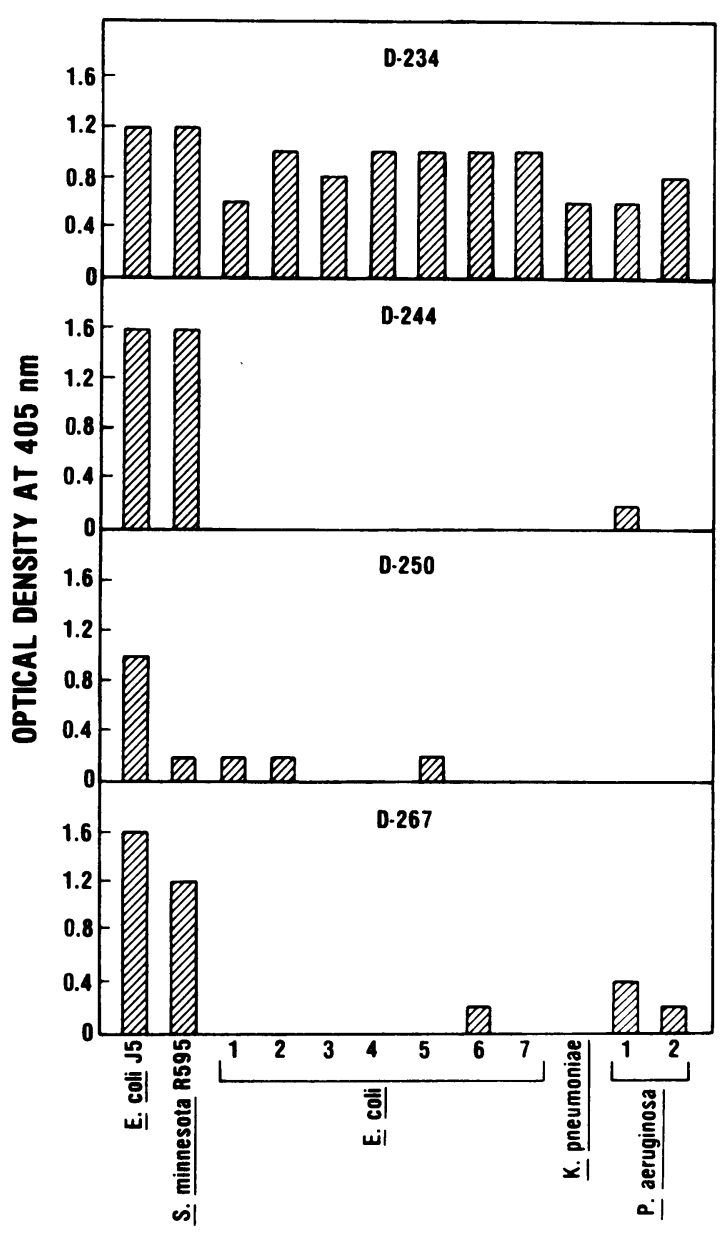

Figure 4. Binding activity of human mAbs against rough and smooth bacteria, measured by ELISA. Tissue culture-derived, ammonium sulfate-precipitated mAbs were assayed at a concentration of $100 \mathrm{ng} / \mathrm{ml}$ against whole bacteria (see Methods). Negative controls (not shown) included D-253 (a Pseudomonas aeruginosa toxin A-specific human IgM $\mathrm{mAb}$ ) assayed against all strains shown, and each $\mathrm{mAb}$ assayed against two streptococcal strains and one Bacillus species organism.

LPS per se. In contrast, D-234 recognized its epitope as part of a larger (i.e., slightly slower migrating) core structure in the case of smooth LPS from $E$. coli 0111:B4 (lane 1) and $P$. aeruginosa Fisher immunotype 2 (lane 19). In no case, apparently, was this determinant recognized by D-234 in a slower migrating O-side chain-containing smooth LPS molecule. The consistent pattern demonstrated by mAb D-234 in all of these immunoblots indicated better epitope recognition in rough mutant LPS (particularly when this represented the $R e$ chemotype), and/or free lipid A, than in smooth parent or wild type LPS. Immunoblotting with D-234 also confirmed its cross-reactivity among $E$. coli strains derived from different $\mathrm{O}$-antigenic types, Salmonella and other representative genera from the family Enterobacteriaceae, as well as at least one member of the Pseudomonadaceae.

The mAb D-250 reacted selectively with LPS from the Rc chemotype of $S$. minnesota, the analogous $\mathrm{J} 5$ mutant of $E$. coli 0111:B4, and the $E$. coli $\mathrm{K} 12 \mathrm{BB} 26: 36$ strain which on silverstained SDS-PAGE gels also appeared to lack O-side chains (Fig. 5; lanes 10,2 , and 4, respectively). The recognition by D-250 of its epitope in the Rc form of $S$. minnesota LPS, alone among the various rough chemotypes tested, confirmed the specificity of this $\mathrm{mAb}$ for a determinant in the core oligosaccharide and underscored the importance of adequate epitope exposure. The apparent reactivity of D-250 with $E$. coli J5 lipid A (lane 3 ) reflects probable contamination of the lipid A preparation with unhydrolyzed J5 LPS, as described above. Supporting this interpretation were the intense staining of this lipid A preparation on silver-stained SDS-PAGE gels (weak or absent in the case of other lipid As-see lanes 6,13,15, and 16); the presence of $\mathrm{KDO}$, as revealed by thiobarbituric acid assay; and the absence of reactivity of D-250 with other lipid As (lanes 6, 13, and 15). The observation that binding patterns developed with mAb D250 appeared to be broader and to embrace somewhat slower migrating molecular species than those produced in immunoblots with D-234 also indicated that D-250 recognized a more distal determinant in the incomplete core oligosaccharide. Conversely, D-234, but not D-250, reacted strongly with a monophosphoryl derivative of $S$. typhimurium lipid A (Fig. 5, lane 16) and more faintly with the lipid A precursor molecule designated lipid $\mathrm{X}$ (lane 17). The latter was demonstrated more convincingly on "dot blots" (not shown). These results indicated that D-234 recognizes an epitope on a lipid A part structure comprised of a single, substituted glucosamine residue with its attached long-chain fatty acids, and that the minimum structure recognized by D-234 may not necessarily include a phosphate group.

Antibody avidity. The mAb, D-234, demonstrated high avidity on the basis of Scatchard analyses of binding data obtained employing $E$. coli J5 and $S$. minnesota R595 core glycolipids, or free lipid As, as solid-phase antigens in a radioimmunoassay (Table II). The binding constants were somewhat higher for free lipid As compared with the corresponding core glycolipids. It was thus documented that a broadly cross-reactive lipid A-specific mAb may display high avidity for an epitope shared by phylogenetically distinct gram-negative bacteria.

Inhibition of $m A b$ s by polymyxin $B$. It is well known that the cell wall-active cationic antibiotic, polymyxin $B$, inhibits many of the biologic activities of LPS on the basis of its specific interaction with the lipid A moiety (51). It was therefore of interest to examine the possible inhibitory effect of polymyxin B on the reactivity of core-specific mAbs with their respective epitopes. Using the competitive inhibition ELISA format described above and graded concentrations of polymyxin B inhibitor, we demonstrated dose-dependent inhibition of binding by the lipid A-specific mAbs D-234 and D-267 (Fig. 6, left panel). In contrast, polymyxin $B$ exerted no effect on binding by the core oligosaccharide-reactive D-250 antibody (left panel) or a murine mAb (PIC9.1.1, right panel), included for comparative purposes, that recognizes a determinant in the O-specific side chain of $P$. aeruginosa immunotype 1 LPS (52). It is reasonable to assume that the relative inhibitory effects of polymyxin $B$ on the reactivity of LPS-specific mAbs depends on the proximity of the polymyxin $B$ and antibody combining sites on the LPS macromolecule. The above results suggest that at least some antibodies reactive with epitopes on the lipid A moiety are distinguishable from those whose antigenic determinants are located in the core oligosaccharide, or LPS O-side chain, on the basis of their susceptibility to inhibition by polymyxin $B$.

\section{Discussion}

The achievement of stable in vitro synthesis of human mAbs with high functional affinity for conserved epitopes on the bio- 


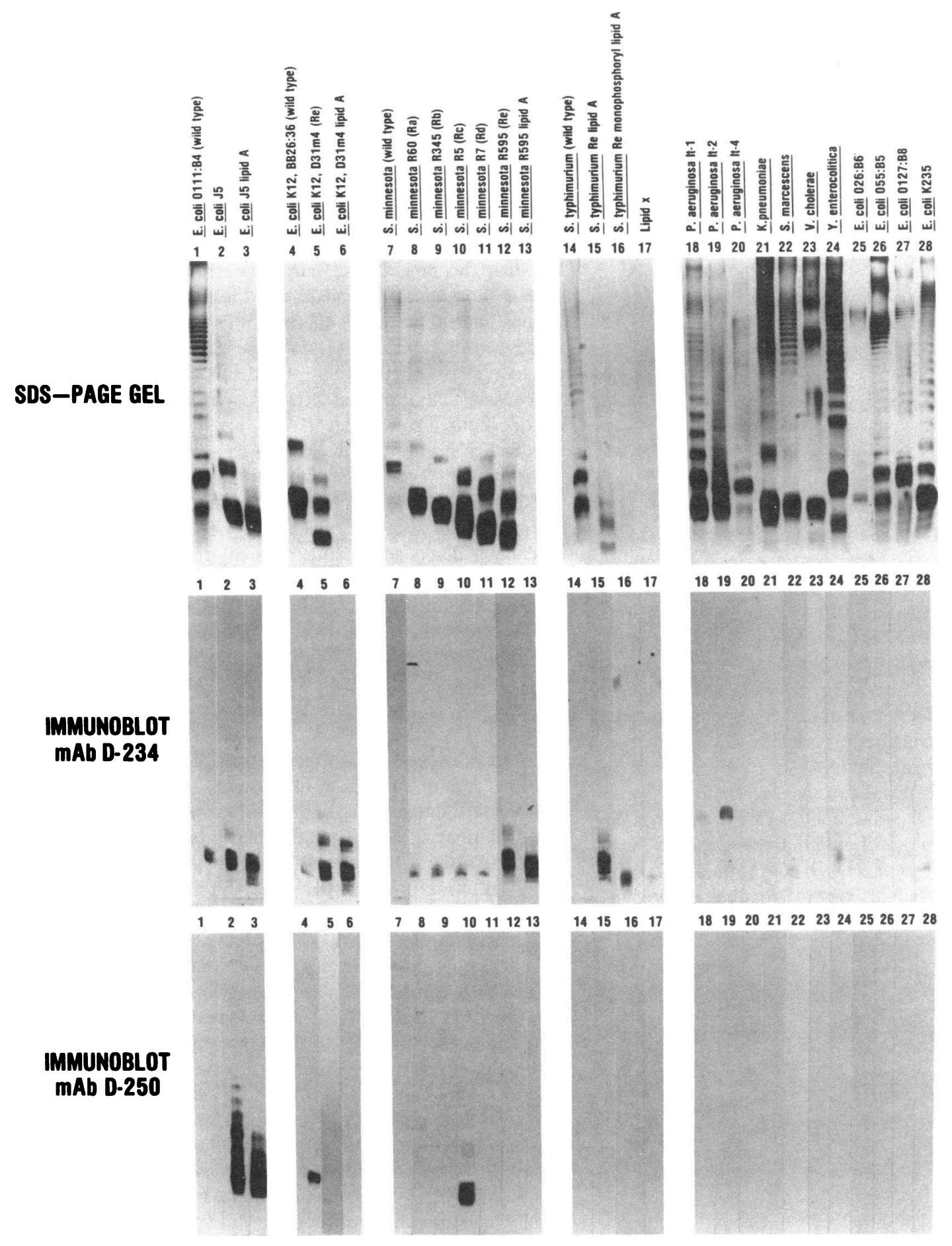

Figure 5. Immunoblot analysis of human mAbs reactive with epitopes in the core-lipid A region of LPS. Lipid A and LPS were applied to $14 \%$ SDS-PAGE in 5 and $10 \mu \mathrm{g}$ quantities, respectively. Gels in the upper panel were silver-stained to demonstrate LPS migration pat-

logically active lipid A moiety of LPS has important theoretical and practical implications. Characterization of these antibodies confirms the presence of conserved epitopes in the core-lipid A complex that are shared by a wide variety of gram-negative bacteria, including those that are pathogenic for man. These findings also prove the existence of human B cell clones with the potential for secreting IgM antibodies that recognize such conserved epitopes in the core region of LPS.

terns. (Note variable staining of lipid As.) Identical companion gels were utilized for immunoblots developed with mAbs D-234 and D250 (middle and lower panels, respectively), which were employed at a concentration of $50 \mu \mathrm{g} / \mathrm{ml}$. See text for more detailed description.

By documenting the cross-reactivity of mAbs like D-234 with a variety of free lipid As, our analyses confirmed the conservation of lipid A-associated antigenic determinants among LPS from different O-antigenic types of $E$. coli as well as among other members of the Enterobacteriaceae and Pseudomonadaceae. The variable binding exhibited by lipid A-reactive mAbs vis-a-vis hydrolyzed LPS other than those derived from $E$. coli and Salmonella may have reflected naturally occurring differences 
Table II. Equilibrium Binding Constants of the Human mAb, D-234, Determined Using Rough LPS or Free Lipid As as Solid-phase Antigens in a Radioimmunoassay

\begin{tabular}{ll}
\hline Antigen & $\mathrm{Ka}^{*}$ \\
\hline E. coli J5 LPS & $-4.06 \times 10^{9} \mathrm{M}^{-1}$ \\
S. minnesota R595 LPS & $-4.56 \times 10^{9} \mathrm{M}^{-1}$ \\
E. coli K12 lipid A & $-1.60 \times 10^{10} \mathrm{M}^{-1}$ \\
S. minnesota R595 lipid A & $-1.53 \times 10^{10} \mathrm{M}^{-1}$ \\
\hline
\end{tabular}

among bacterial species in respect to lipid A structure and/or variable susceptibility of particular epitopes to structural or conformational alteration resulting from acid hydrolysis as carried out in this study. Interestingly, antisera included as "positive controls," which recognized determinants in the exposed O-side chain of smooth LPS, produced almost equivalent high reactivity against hydrolyzed and unhydrolyzed homologous LPS (Table I). In contrast, these antisera demonstrated low reactivity against heterologous smooth LPS, but marked enhancement in epitope recognition following release of free lipid $\mathrm{A}$ by acid hydrolysis comparable to that observed in the case of lipid A-reactive mAbs. Thus, shared antigenic determinants in the core-lipid A region of LPS must be exposed in order to be recognized by core-specific antibodies, whether of monoclonal or polyclonal origin. Yet immunization with what are thought to be intact, O-side chain containing LPS molecules results in antibody responses to core structures as well as $\mathrm{O}$-side chains, presumably through in vivo mechanisms that unmask core epitopes.

Our data indicate that the O-specific side chain and core oligosaccharide of LPS restrict antibody access to epitopes in the core region of that molecule. Similar conclusions were reached by Nelles and Niswander (17), by Gigliotti and Shenep (19), and by Miner et al. (20), based on data obtained employing murine mAbs with specificities comparable to those of the hu-

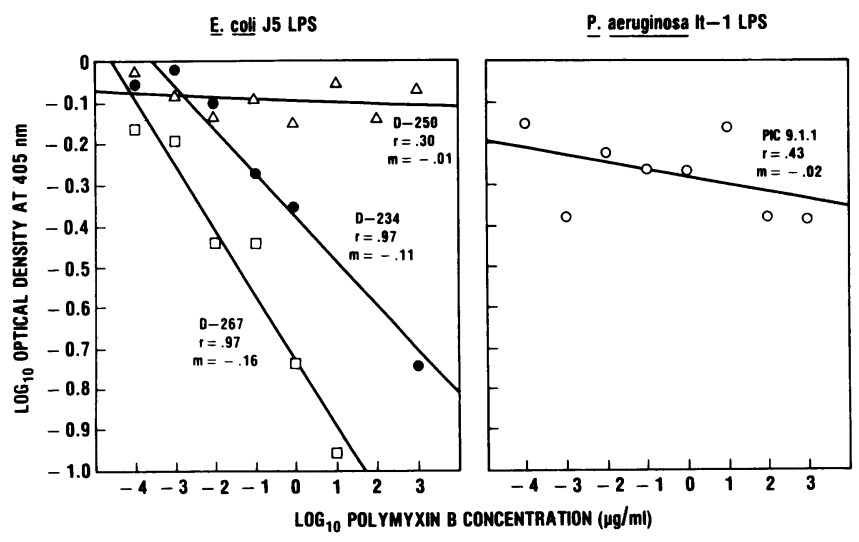

Figure 6. Competitive inhibition of LPS-reactive mAbs by polymyxin B. 10-fold dilutions of polymyxin B were incubated at room temperature for $30 \mathrm{~min}$ in polystyrene microtiter wells previously coated with $25 \mu \mathrm{g} / \mathrm{ml}$ of the purified LPS indicated above each panel. An equal volume of $\mathrm{mAb}(500 \mathrm{ng} / \mathrm{ml})$ was then added to each well, the mixtures incubated an additional $30 \mathrm{~min}$, and the amount of $\mathrm{mAb}$ bound to LPS measured by ELISA. The murine mAb, PIC9.1.1, which reacts with an O-side chain determinant on Pseudomonas aeruginosa Fisher immunotype 1 (It-1) LPS, is included for comparative purposes (right). man mAbs described here. In each instance, core-reactive mouse antibodies demonstrated little binding activity against isolated smooth LPS. These findings underscore the likelihood that the clinical efficacy of core-specific mAbs will depend to a considerable degree on the molecular forms assumed by LPS in vivo. The demonstration of high levels of naturally acquired antibodies to LPS core determinants in human sera $(8,9)$ suggests that these epitopes, which are not readily accessible to antibodies in in vitro binding assays employing purified LPS, are exposed in vivo. Perhaps this results from the in vivo synthesis and release of LPS in incomplete (rough) forms, or from in vivo processing such as biochemical degradation of LPS by host enzymes (53). It is of interest, in this connection, that although the lipid Areactive $m A b s, D-244$ and D-267, and the core oligosaccharidereactive $\mathrm{mAb}, \mathrm{D}-250$, demonstrated generally low binding activity against clinical isolates, D-234, which also reacts with an epitope on lipid A, was able to recognize that epitope in situ on a variety of phenotypically smooth bacteria. This finding was consistent with those obtained using mouse antibodies, by Nelles and Niswander (17) and by Miner et al. (20). The particular anti-core mAbs generated by Gigliotti and Shenep (19), on the other hand, demonstrated little reactivity against a limited number of smooth bacteria. In the case of D-234, whole cell binding was maximal during the early log phase of bacterial growth, but diminished markedly thereafter. This suggested, at least in the case of cell-associated LPS, that intermediate or incomplete forms of the LPS molecule with relatively exposed core determinants may be produced early in the normal bacterial growth cycle.

A previous study (18) reported the identification of a hybridoma, resulting from the fusion of B lymphocytes from a "sensitized" human spleen with heteromyeloma cells, that produced a human IgM antibody that purportedly reacted with all rough and smooth LPS and all gram-negative bacterial isolates examined. It was further asserted that this antibody neutralized each of two LPS employed in the induction of local Shwartzman reactions and protected, without exception, against each of five phenotypically smooth heterologous gram-negative bacteria in live challenge experiments. Although the lipid A specificity and cross-reactivity of the human mAb described in this previous study suggested similarities to the human mAbs reported here, the uniformly positive binding and functional activities of this $\mathrm{mAb}$ vis-a-vis all rough and smooth LPS (and bacteria) tested were not fully consistent with our results, or with those reported by others in respect to murine mAbs with similar specificities $(17,19,20)$. Until these findings are fully corroborated by other laboratories, final judgment must be reserved regarding their validity in relation to our own data.

The uncertainty that exists concerning the physical and chemical forms assumed by LPS in vivo, and their biologic impact, complicates experimental inquiries into the functional activities expressed in vivo by mAbs that recognize determinants in the core-lipid A complex. Of particular interest is whether antibodies that react with epitopes on lipid A, or the closely associated core oligosaccharide, function as antitoxins with true endotoxin-neutralizing activity (54-56); facilitate clearance by the reticuloendothelial system of endotoxin or bacteria bearing LPS on their surface (57); or mediate direct, complement-dependent or independent bactericidal or opsonic functions (10). Clearly, further immunochemical and functional analysis of the human mAbs described here, and others like them, will provide basic new insights concerning the immunopathogenic role of 
LPS, as well as the therapeutic potential of the antibodies themselves.

\section{Acknowledgments}

We thank for their superb technical assistance Nancy L. Koles, Maryalice Miller, David E. Avigan, Bradley J. Dyer, Sarah M. Hart, George Senyk, Janet Wong, Howard Weintraub, David Lippmann, and Patricia Hummel. We are grateful to Angela B. James for her help in preparing the manuscript.

Supported in part by grant AI-22706 from the National Institute of Allergy and Infectious Diseases and by the Uniformed Services University of the Health Sciences Protocol No. C08312.

\section{References}

1. Reitschel, E. Th., V. Schade, M. Jensen, H.-W. Wollenweber, O. Luderitz, and S. G. Greisman. 1982. Bacterial endotoxins: chemical structure, biological activity and role in septicemia. Scand. J. Infect. Dis. 31:8-21.

2. Young, L. S. 1984. Gram-negative sepsis. In Principles and Practice of Infectious Diseases. G. L. Mandell and R. G. Douglas, editors. John Wiley and Sons, New York. 452-475.

3. Luderitz, O., K. Tanamoto, C. Galanos, G. R. McKenzie, H. Brade, V. Zahringer, E. Th. Rietschel, S. Usumoto, and T. Shiba. 1984. Lipopolysaccharides: structural principles and biologic activities. Rev. Infect. Dis. 6:428-431.

4. Rietschel, E. Th., H. W. Wollenweber, R. Russa, and V. Zahringer. 1984. Concepts of the chemical structure of lipid A. Rev. Infect. Dis. 6: 432-438.

5. Luderitz, O., A. M. Staub, and O. Westphal. 1966. Immunochemistry of $\mathrm{O}$ and $\mathrm{R}$ antigens of Salmonella and related Enterobacteriaceae. Bacteriol. Rev. 30:192-255.

6. Young, L. S. 1972. I. In vitro interaction of bacteria, polymorphonuclear leukocytes, and serum factors. J. Infect. Dis. 126:257-276.

7. Chedid, L., M. Parant, F. Parant, and F. Boyer. 1968. A proposed mechanism for natural immunity to enterobacterial pathogens. J. Immunol. 100:292-301.

8. Pollack, M., A. I. Huang, R. K. Prescott, L. S. Young, K. W. Hunter, D. F. Cruess, and C.-M. Tsai. 1983. Enhanced survival in Pseudomonas aeruginosa septicemia associated with high levels of circulating antibody to Escherichia coli endotoxin core. J. Clin. Invest. 72:18741881.

9. Stoll, B. J., M. Pollack, and J. A. Hooper. 1987. Antibodies to endotoxin core determinants in normal human plasma and in immune globulin for intravenous use. Serodiagnosis and Immunotherapy. In press.

10. McCabe, W. R. 1972. Immunization with R mutants of S. minnesota. I. Protection against challenge with heterologous Gram-negative bacilli. J. Immunol. 108:601-610.

11. Ziegler, E. J., H. Douglas, J. E. Sherman, C. E. Davis, and A. I. Braude. 1973. Treatment of $E$. coli and Klebsiella bacteremia in agranulocytic animals with antiserum to UDP-gal epimerase-deficient mutant. J. Immunol. 111:433-438.

12. Ziegler, E. J., J. A. McCutchan, J. Fierer, M. P. Glauser, J. C. Sadoff, H. Douglas, and A. I. Braude. 1982. Treatment of Gram-negative bacteremia and shock with human antiserum to a mutant Escherichia coli. N. Engl. J. Med. 307:1225-1230.

13. Elbein, A. D., and E. C. Heath. 1965. The biosynthesis of cell wall lipopolysaccharide in Escherichia coli. I. The biochemical properties of a uridine diphosphate galactose-4-epimeraseless mutant. J. Biol. Chem. 240:1919-1925.

14. Pollack, M., and K. W. Hunter. 1983. Monoclonal antibodies reactive with endotoxin core of Gram-negative bacteria. In Abstracts of the 23rd Interscience Conference on Antimicrobial Agents and Chemotherapy. Washington, D. C., American Society for Microbiology. 195. (Abstr.)

15. Raubitschek, A. A., M. Pollack, and J. W. Larrick. 1985. Prep- aration of human monoclonal antibodies that react with the conserved core region of endotoxin. Clin. Res. 33:416A. (Abstr.)

16. Mutharia, L. M., G. Crockford, W. C. Bogard, Jr., and R. E. W. Hancock. 1984. Monoclonal antibodies specific for Escherichia coli J5 lipopolysaccharide: cross-reaction with other Gram-negative bacterial species. Infect. Immun. 45:631-636.

17. Nelles, M. J., and C. A. Niswander. 1984. Mouse monoclonal antibodies reactive with $\mathrm{J} 5$ lipopolysaccharide exhibit extensive serological cross-reactivity with a variety of Gram-negative bacteria. Infect. Immun. 46:677-681.

18. Teng, N. N. H., H. S. Kaplan, J. M. Hebert, C. Moore, H. Douglas, A. Wunderlich, and A. I. Braude. 1985. Protection against Gram-negative bacteremia and endotoxemia with human monoclonal IgM antibodies. Proc. Natl. Acad. Sci. USA. 82:1790-1794.

19. Gigliotti, F., and J. L. Shenep. 1985. Failure of monoclonal antibodies to core glycolipid to bind intact smooth strains of Escherichia coli. J. Infect. Dis. 151:1005-1011.

20. Miner, K. M., C. L. Manyak, E. Williams, J. Jackson, M. Jewell, M. T. Gammon, C. Ehrenfreund, E. Hayes, L. T. Callahan III, H. Zweerink, and N. H. Sigal. 1986. Characterization of murine monoclonal antibodies to Escherichia coli J5. Infect. Immun. 52:56-62.

21. Galanos, C., O. Luderitz, and O. Westphal. 1969. A new method for the extraction of R lipopolysaccharides. Eur. J. Biochem. 9:245-249.

22. Westphal, O., and K. Jann. 1965. Bacterial lipopolysaccharides: extraction with phenol-water and further applications of the procedure. Methods Carbohydrate Chem. 5:83-90.

23. Galanos, C., M. A. Freudenberg, F. Jay, D. Nerkor, K. Veleva, H. Brade, and W. Strittmatter. 1984. Immunogenic properties of lipid A. Rev. Infect. Dis. 6:546-552.

24. Qureshi, N., K. Takayama, and E. Ribi. 1982. Purification and structural determination of nontoxic lipid A obtained from the lipopolysaccharide of Salmonella typhimurium. J. Biol. Chem. 257:1180111815.

25. Takayama, K., N. Qureshi, P. Mascagni, M. A. Nashed, L. Anderson, and C. R. H. Raetz. 1983. Fatty acyl derivatives of glucosamine1-phosphate in Escherichia coli and their relation to lipid A. J. Biol. Chem. 258:7379-7385.

26. Böyum, A. 1968. Separation of leukocytes from blood and bone marrow. Scand. J. Lab. Clin. Invest. 21(Suppl 97):77.

27. Madsen, M., and H. E. Johnsen. 1979. A methodologic study of E-rosette formation using AET-treated sheep red blood cells. J. Immunol. Methods. 27:61-74.

28. Miller, G., and M. Lipman. 1973. Release of infectious EpsteinBarr virus by transformed marmoset leukocytes. Proc. Natl. Acad. Sci. USA. 70:190-194.

29. Foung, S. K. H., S. Perkins, A. Raubitschek, J. Larrick, G. Lizak, D. Fishwild, E. G. Engleman, and F. C. Grumet. 1984. Rescue of human monoclonal antibody production from an EBV-transformed B cell line by fusion to a human-mouse hybridoma. J. Immunol. Methods. 70:8390.

30. Larrick, J. W., B. J. Dyer, G. Senyk, S. M. Hart, R. Moss, D. Lippman, M. C. Jahnsen, J. Wang, H. Weintraub, and A. A. Raubitschek. 1985. In vitro expansion of human B cells for the production of human monoclonal antibodies. In Human Hybridomas and Monoclonal Antibodies. E. G. Engleman, S. K. H. Foung, J. W. Larrick, and A. A. Raubitschek, editors. Plenum Press, New York. 149-165.

31. Gronowicz, E., A. Continho, and F. Melchers. 1976. A plaque assay for all cells secreting Ig of a given type or class. Eur. J. Immunol. 6:588-590.

32. Buck, D. W., J. W. Larrick, A. Raubitschek, K. E. Truitt, G. Senyk, J. Wang, and B. J. Dyer. 1984. Production of human monoclonal antibodies. In Monoclonal Antibodies and Functional Cell Lines. R. H. Kennet, K. B. Bechtol, and T. J. McKearn, editors. Plenum Press, New York. 275-309.

33. Maniatus, T., E. F. Fritsh, and J. Sambrook. 1982. Molecular Cloning. Cold Spring Harbor Laboratory, Cold Spring Harbor, New York.

34. Berger, S. L., and Birkenmeier. 1979. Inhibition of intractable 
nucleases with ribonucleoside-vanadyl complexes: isolation of messenger ribonucleic acid from resting lymphocytes. Biochemistry. 18:5143-5148.

35. Lehrach, H., D. Diamond, J. M. Wozney, and H. Boedtker. 1977. RNA molecular weight determinations by gel electrophoresis under denaturing conditions, a critical re-examination. Biochemistry. 16:47434750.

36. Ono, M., M. D. Cole, A. T. White, and R. C. C. Huang. 1980. Sequence organization of cloned intracisternal A-particle genes. Cell. 21: 465-473.

37. Copeland, N. G., A. D. Zelenetz, and G. M. Cooper. 1980. Transformation by subgenomic fragments of Rous sarcoma virus DNA. Cell. 19:863-870.

38. Southern, E. 1975. Detection of specific sequences among DNA fragments separated by gel electrophoresis. J. Mol. Biol. 98:503-517.

39. Wahl, G., M. Stern, and G. Stark. 1979. Efficient transfer of large DNA fragments from agarose gels to diazobenzyloxymethyl-paper and rapid hybridization using dextran-sulfate. Proc. Natl. Acad. Sci. USA. 76:3683-3687.

40. Gazitt, Y., A. D. Deitch, P. A. Marks, and R. A. Rifkind. 1978. Cell volume changes in relation to the cell cycle of differentiating erythroleukemic cells. Exp. Cell. Res. 117:413-420.

41. Cram, L. S., E. R. Gomez, C. O. Thoen, J. C. Forslund, and J. H. Jett. 1976. Flow microfluorometric quantitation of the blastogenic response of lymphocytes. J. Histochem. Cytochem. 24:383-387.

42. Diamond, L. W., and R. C. Braylan. 1980. Flow analysis of DNA content and cell size in non-Hodgkin's lymphoma. Cancer Res. 40:703712.

43. Laemmli, U. K. 1970. Cleavage of structural proteins during the assembly of the head of the bacteriophage $T_{4}$. Nature (Lond.). 227:680685.

44. Maizel, J. V. 1971. Polyacrylamide gel electrophoresis of viral proteins. Methods Virol. 5:179-246.

45. Tsai, C.-M., and C. E. Frasch. 1982. A sensitive silver stain for detecting lipopolysaccharides in polyacrylamide gels. Anal. Biochem. 119: 115-119.

46. Towbin, H., T. Staehelin, and J. Gordon. 1979. Electrophoretic transfer of proteins from polyacrylamide gels to nitrocellulose sheets: procedure and some applications. Proc. Natl. Acad. Sci. USA. 76:43504354.

47. Hitchcock, P. J., and T. M. Brown. 1983. Morphological heterogeneity among Salmonella lipopolysaccharide chemotypes in silverstained polyacrylamide gels. J. Bacteriol. 154:179-246.

48. Frankel, M. E., and W. Gerhard. 1979. The rapid determination of binding constants for antiviral antibodies by a radioimmunoassay. An analysis of the interaction between hybridoma proteins and influenza virus. Mol. Immunol. 16:101-106.

49. Mandrell, R. E., and W. D. Zollinger. 1982. Measurement of antibodies to meningococcal group B polysaccharide: low avidity binding and equilibrium binding constants. J. Immunol. 129:2172-2178.

50. Goldman, R. C., and L. Lieve. 1980. Heterogeneity of antigenicside-chain length in lipopolysaccharide from Escherichia coli 0111 and Salmonella typhimurium LT2. Eur. J. Biochem. 107:145-153.

51. Morrison, D. C., and D. M. Jacobs. 1976. Binding of polymyxin $\mathrm{B}$ to the lipid A portion of bacterial lipopolysaccharides. Immunochem istry. 13:813-818.

52. Stoll, B. J., M. Pollack, L. S. Young, N. Koles, R. Gascon, and G. B. Pier. 1986. Functionally active monoclonal antibody that recognizes an epitope on the $\mathrm{O}$ side chain of Pseudomonas aeruginosa immunotype1 lipopolysaccharide. Infect. Immun. 53:656-662.

53. Hall, C. L., and R. S. Munford. 1983. Enzymatic deacylation of the lipid A moiety of Salmonella typhimurium lipopolysaccharide by human neutrophils. Proc. Natl. Acad. Sci. USA. 80:6671-6675.

54. Braude, A. I., and H. Douglas. 1972. Passive immunization against the local Shwartzman reaction. J. Immunol. 108:505-512.

55. Braude, A. I., H. Douglas, and C. E. Davis. 1973. Treatment and prevention of intravascular coagulation with antiserum to endotoxin. $J$. Infect. Dis. 128(Suppl.):S157-S165.

56. Rietschel, E. Th., and C. Galanos. 1977. Lipid A antiserummediated protection against lipopolysaccharide- and lipid A-induced fever and skin necrosis. Infect. Immun. 15:34-49.

57. Young, L. S., P. Stevens, and J. Ingram. 1975. Functional role of antibody against "core" glycolipid of Enterobacteriaceae. J. Clin. Invest. $56: 850-861$. 